\title{
ANÁLISE DA TENSÃO DE CISALHAMENTO EM HIDROCICLONES PARA A SEPARAÇÃO DE CÉLULAS ANIMAIS
}

\author{
R. P. DOS ANJOS ${ }^{1}$, R. A. MEDRONHO ${ }^{1}$ e A. FIGUEREDO-CARDERO ${ }^{2}$ \\ ${ }^{1}$ Universidade Federal do Rio de Janeiro, Departamento de Engenharia Química \\ ${ }^{2}$ Fundação Oswaldo Cruz \\ E-mail para contato: rodrigopanjos1@ hotmail.com
}

\begin{abstract}
RESUMO - O presente trabalho buscou geometrias que minimizassem a tensão de cisalhamento em um hidrociclone para separação de células animais. Foi utilizada a fluidodinâmica computacional, CFD, através do pacote comercial da Ansys 13.0, para efetuar o trabalho. As simulações foram todas monofásicas (só se considerou o meio de cultivo). As mesmas foram realizadas no software Fluent $13.0 \mathrm{com}$ malhas hexaédricas confeccionadas no ICEM 13.0 e modelo de turbulência RSM. As configurações aplicadas foram validadas com a geometria base. Foi verificado que as tensões na parede eram muito superiores às tensões cisalhantes no seio do fluido. As regiões de transição entre o tubo de entrada e o corpo do equipamento, próxima à entrada e no tubo de underflow mostraram ter as maiores tensões na parede. A geometria com tubo de underflow $15^{\circ}$ foi eficiente em diminuir a tensão na parede neste tubo. Entretanto, as geometrias com tubo de entrada de seção reta retangular e a voluta não concederam queda nas tensões na parede próximas à entrada. Portanto, apenas a modificação relativa ao tubo de underflow cumpriu o objetivo desejado.
\end{abstract}

\section{INTRODUÇÃO}

Com o advento da biotecnologia, diversos bioprocessos envolvendo células animais vêm sendo desenvolvidos especialmente relacionados à indústria farmacêutica.

Visando à produção industrial de produtos relacionados às células animais, foram criados diversos biorreatores e formas de operá-los. O maior desafio desses é aumentar a concentração celular a fim de obter-se uma maior produtividade.

Dentre os modos de operação de um biorreator, há o contínuo com retenção de biomassa (perfusão). Ele é o mais indicado para a operação industrial, pois permite a operação em estado estacionário sem perda celular acentuada. Contudo, conforme afirma Chico et al. (2007), a batelada alimentada é o modo mais empregado industrialmente. Tal fato decorre de dificuldades de projeto e operação associados à perfusão, inclusive o equipamento de retenção celular a ser utilizado.

Inúmeros equipamentos já foram utilizados com o fim supracitado. Contudo, os hidrociclones 
apresentam alguns dos requisitos desejados para um equipamento de retenção celular, descritos por Roth et al. (1997, apud Castilho e Medronho, 2002. Tais requisitos são: alta eficiência de separação conforme apresentado por Jockwer (2001), Deckwer et al. (2005), Elsayed et al. (2006), entre outros, pouca necessidade de manutenção por ser um equipamento sem partes móveis, o que também facilita a manutenção de um ambiente asséptico, e baixo tempo de residência. Entretanto, a viabilidade celular pode ser afetada pelas altas tensões de cisalhamento presentes nos hidrociclones, uma vez que as células são susceptíveis às tensões hidrodinâmicas, sendo os danos às células associados à intensidade das tensões de cisalhamento e ao tempo de exposição a elas (Moraes et al., 2007).

Com isso, o presente trabalho visa ao estudo da tensão de cisalhamento dentro do hidrociclone para a separação de células animais proposto por Deckwer et al. (2005) através da fluidodinâmica computacional (CFD). Para a identificação das regiões de maior tensão de cisalhamento foi utilizado o pacote comercial da Ansys CFX 13.0. Feita a avaliação para a geometria base, foram propostas modificações para diminuir os níveis de tensão de cisalhamento nas regiões críticas.

\section{MATERIAIS E MÉTODOS}

\subsection{Materiais}

As etapas necessárias para a execução de uma simulação CFD, criação de geometria, malha, processamento e pós-processamento, foram feitas em um microcomputador com processadores intel quad-core de 2,8 GHz e 4 GB de memória RAM e 800 GB de memória física. Também auxiliou no processamento, um cluster da empresa SGI, constituída de 20 nós duplos contendo 40 processadores Intel Xeon quad-core com $2.33 \mathrm{GHz}, 4 \mathrm{~GB}$ de memória RAM e $250 \mathrm{~GB}$ de memória física. Este equipamento contém ainda um head node com 2 processadores Intel Xeon quad-core de 2,33 $\mathrm{GHz}$ e, 8 GB de memória RAM, e 146 SAS HD. Com isso, tem-se um total de 168 cores com 1 GB de memória RAM cada. Este equipamento conta com um storage de 8 TB de memória física,.

\subsection{Geometria}

A primeira etapa para a realização de um estudo com CFD é a construção da geometria, o que foi feito no programa DesignModeler do pacote da Ansys CFX 13.0.

Neste estudo, foram testados quatro hidrociclones. Como geometria base, foi utilizado o equipamento proposto por Deckwer et al. (2005) e com dimensões mostradas pela Tabela 1. Todas as geometrias apresentam o corpo do equipamento (parte cilíndrica e parte cônica) e overflow idênticos. 
Tabela 1 - Dimensões da geometria base.

\begin{tabular}{|c|c|}
\hline & Dimensão \\
\hline Diâmetro do overflow & $1,5 \mathrm{~mm}$ \\
\hline Prolongamento do overflow & $25,0 \mathrm{~mm}$ \\
\hline Comprimento da seção cilíndrica & $8,0 \mathrm{~mm}$ \\
\hline Tamanho do vortex finder & $2,5 \mathrm{~mm}$ \\
\hline Espessura do vortex finder & $1,0 \mathrm{~mm}$ \\
\hline Ângulo da seção cônica & $6^{\circ}$ \\
\hline Diâmetro do underflow & $2,5 \mathrm{~mm}$ \\
\hline Prolongamento do underflow & $25,0 \mathrm{~mm}$ \\
\hline Diâmetro da seção cilíndrica & $10,0 \mathrm{~mm}$ \\
\hline Diâmetro de entrada & $1,4 \mathrm{~mm}$ \\
\hline Prolongamento da entrada & $25,0 \mathrm{~mm}$ \\
\hline
\end{tabular}

Na geometria 2, foi modificada a saída inferior. Ao invés do tradicional tubo reto presente na geometria base, ela foi desenhada com um tubo de underflow com um ângulo de $15^{\circ}$ e comprimento de $25 \mathrm{~mm}$, semelhante ao exposto por Chu et al. (2000).

Por fim, as geometrias 3 e 4 tiveram alterado o formato do tubo de entrada. Enquanto o hidrociclone de Deckwer et al. (2005) exibe um tubo de entrada tangencial e cilíndrico, a geometria 3 o faz com um paralelepípedo também tangencial de mesmo comprimento e área de seção reta. Já a geometria 4 mantém o formato de entrada voluta, assim denominado por Chu et al. (2000). Todas as geometrias são representadas pela Figura 1.
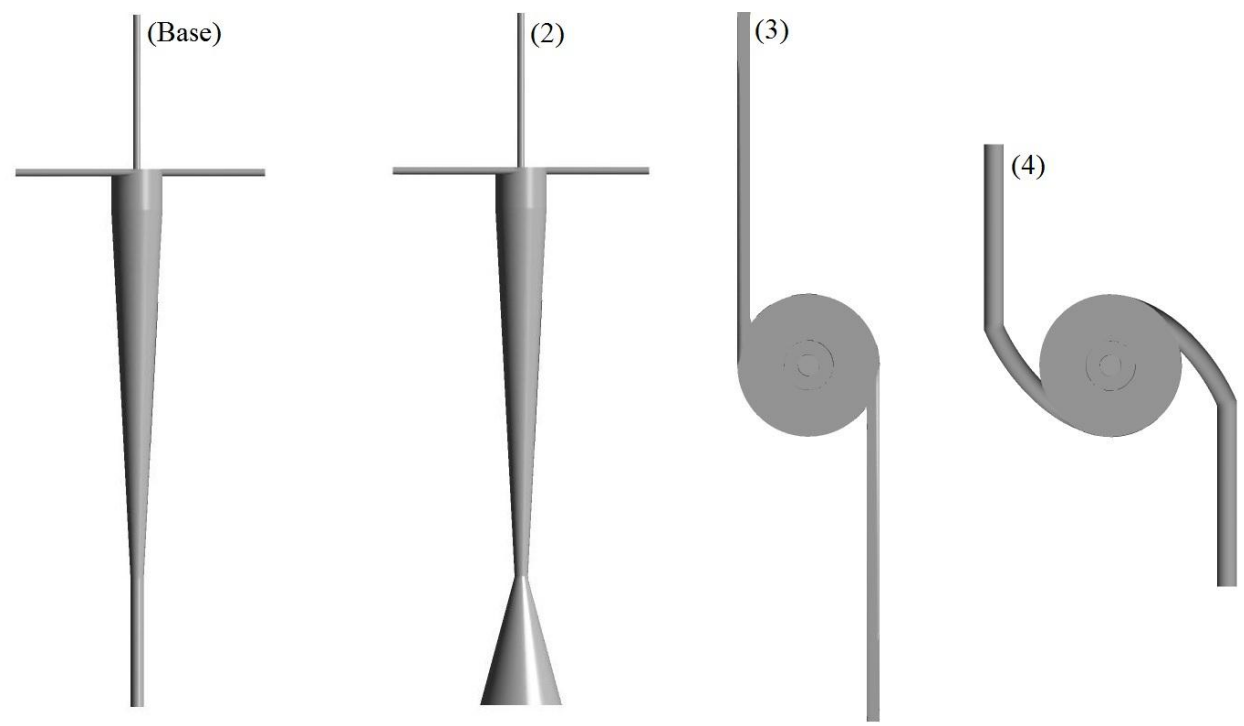

Figura 1 - Geometrias estudadas no presente trabalho. 


\subsection{Malhas}

A segunda etapa foi a confecção das malhas, realizada no ICEM CFD 13.0, com elementos hexaédricos e refino próximo à região central do hidrociclone em virtude do complexo escoamento rotacional reverso e, consequentemente, elevados gradientes de pressão e velocidade. Também foi refinada a região próxima à parede para melhor capturar os elevados gradientes de velocidade lá presentes.

Foram confeccionadas três malhas a fim de efetuar-se o teste de independência de malha com a geometria base, no qual o tamanho de malha é modificado até que não haja mais modificação nas variáveis de interesse com o número de elementos. Dele, foi escolhida a malha 830.920 nós e 851.861 elementos.

O teste de malha e a validação não são mostrados nesse trabalho, mas podem ser encontrados em dos Anjos (2013).

\subsection{Simulações}

A terceira etapa a ser efetuada foi das simulações. Elas foram realizadas no programa Fluent 13.0 .

Todas as simulações foram monofásicas, com as propriedades do meio de cultivo dadas na Tabela 2, e isotérmicas.

Tabela 2 - Propriedades físicas do meio de cultivo utilizadas nas simulações.

\begin{tabular}{|c|c|}
\hline Propriedade & Valor \\
\hline Densidade $\left(\mathrm{g} . \mathrm{cm}^{-3}\right)$ & 1,01 \\
\hline Viscosidade $(\mathrm{cp})$ & 0,70 \\
\hline Temperatura $\left({ }^{\circ} \mathrm{C}\right)$ & 37 \\
\hline Vazão de alimentação $\left(\mathrm{L}^{-} \mathrm{min}^{-1}\right)$ & 1,65 \\
\hline Pressão absoluta na saída superior $(\mathrm{atm})$ & 1,0 \\
\hline Pressão absoluta na saída inferior $(\mathrm{atm})$ & 1,0 \\
\hline
\end{tabular}

A velocidade de entrada foi obtida a partir do valor de vazão da tabela anterior e é igual a 8,93 m. $\mathrm{s}^{-1}$. Tais valores são semelhantes a um dos testes realizados por Jockwer (2001) e permitiu a validação das simulações.

Quanto às configurações adotadas, foi escolhido o tipo de solução Pressure-based, formulação de velocidade relativa, modelo de turbulência RSM, regime estacionário (pseudotransiente), tratamento próximo à parede com funções de parede padrão e esquema acoplado de acoplamento pressão-velocidade. Além disso, foi selecionada a least square cell based como discretização espacial para o gradiente e segunda ordem upwind para discretização espacial de pressão, momento, energia cinética turbulenta e tensores de Reynolds. 
Para a verificação de convergência, foi avaliado o comportamento dos perfis de velocidade tangencial e pressão ao longo de quatro linhas do hidrociclone, 8, 20, 40 e $60 \mathrm{~mm}$ abaixo do topo da seção cilíndrica a cada cinco mil iterações. O mesmo foi feito com os valores de queda de pressão e razão de fluido. A simulação foi considerada convergida quando o valor anterior apresentava erro relativo inferior a $5 \%$ em relação ao novo valor. Isso foi analisado para todas as variáveis. Ademais, o imbalance, razão entre a massa que deixa e a que entra no equipamento, foi mantido inferior a $0,5 \%$ para todas as simulações. As simulações apresentaram convergência com 15 mil iterações e demoraram aproximadamente um dia e meio cada.

A última etapa do trabalho, o pós-processamento, foi realizado no programa CFD-Post 13.0.

\section{RESULTADOS E DISCUSSÃO}

O primeiro teste feito foi avaliar a intensidade das tensões de cisalhamento turbulenta no seio do fluido e a tensão na parede para a geometria base.

Através do teste supracitado, foi observado que as maiores tensões eram encontradas na parede, sendo seu valor médio até sete ordens de grandeza superior aos encontrados no seio do fluido, ordem de grandeza de $10^{2}$ para a primeira e $10^{-4}$ para o segundo. Mesmo quando considerado valor máximo, a tensão cisalhante no seio do fluido apresenta resultados duas ordens de grandeza inferior ao de tensão na parede $\left(1\right.$ contra $\left.10^{2}\right)$.

Sendo assim, foram avaliadas quais regiões do hidrociclone, teste feito com a geometria base, apresentam as maiores tensões de parede. A Figura 2 mostra a superfície externa do hidrociclone colorida em função do valor da tensão na parede.

A partir da Figura 2, foi verificado que as regiões com maior tensão estão próximas à entrada, na transição entre o tubo de entrada e o corpo do equipamento, na parte superior da região cilíndrica e, em menor escala, no tubo da saída inferior.

Na primeira região citada, a elevada tensão na parede pode ser fruto de erro numérico, pois a região de entrada apresenta os piores valores para os critérios de malha dentro de todo o equipamento. A tensão elevada na transição entre o duto de alimentação e o corpo cilíndrico se deve, provavelmente, aos elevados gradientes de velocidade aí existentes face ao súbito alargamento da seção transversal de escoamento. Já a elevada tensão na parede da região cilíndrica pode ser resultado do efeito de jato provocado pelo duto de alimentação. Finalmente, as médias tensões no tubo de underflow podem ser resultantes do aumento de velocidade que ocorre nesta região.

Com isso, foram propostas novas geometrias, a 2 a fim de diminuir a tensão no tubo de underflow e as outras duas, 3 e 4, a fim de diminuir a tensão próxima à região de entrada e na transição entre o tubo de entrada e o corpo do equipamento. 


\section{Tensão na parede}

$5.408 e+002$

$4.142 e+002$

$2.876 e+002$

$1.611 e+002$

$3.454 e+001$

[Pa]

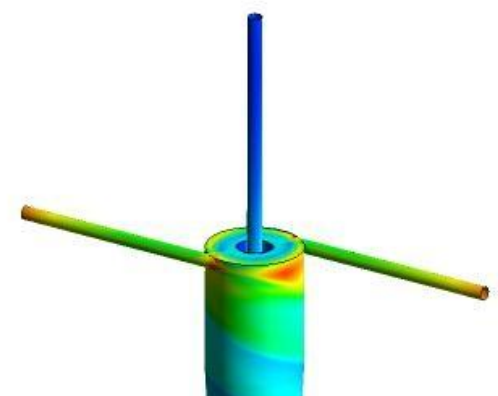

Figura 2 - Análise da tensão na parede para a geometria base.

Com isso, foram propostas novas geometrias, a 2 a fim de diminuir a tensão no tubo de underflow e as outras duas, 3 e 4, a fim de diminuir a tensão próxima à região de entrada e na transição entre o tubo de entrada e o corpo do equipamento.

A primeira comparação foi feita entre as geometrias base e 2, em que foi constatada a diminuição da intensidade da tensão na parede do tubo de underflow, excetuando a região de transição entre o corpo do equipamento e o tubo da saída inferior.

Os níveis de tensão na parede no tubo de underflow da geometria base, que representa $8,5 \%$ da área superficial do equipamento, variaram entre 240 e 330 Pa. Já na geometria 2, o tubo de underflow, que representa $26,3 \%$ da área superficial do hidrociclone, a tensão na parede está na faixa de 4 a 220 $\mathrm{Pa}$ e ela decresce em direção à parte inferior do tubo. A pequena região com altos valores de tensão ao 
final da seção cônica do corpo do hidrociclone e início da seção cônica do underflow representa apenas $0,3 \%$ da área superficial do equipamento, mas apresenta níveis de tensão na parede entre 400 e $430 \mathrm{~Pa}$ na sua maior parte e uma região mínima com intensidade de $500 \mathrm{~Pa}$.

Esta diminuição da tensão na parede do tubo de underflow para a geometria 2 representou uma queda relativa à geometria base de $20,0 \%$ no valor médio desta variável ao longo do hidrociclone, de $213 \mathrm{~Pa}$ para $170 \mathrm{~Pa}$.

Tal queda no valor de tensão média na parede na região supracitada é resultado da queda da velocidade no tubo de underflow na geometria 2 quando comparada à base. No que tange à pequena região que resultou em um aumento no valor máximo, ela é fruto da transição brusca entre o corpo do equipamento e o tubo da saída inferior. Sendo assim, uma transição mais suave provavelmente reduziria o problema.

Portanto, a geometria 2 se mostra promissora para o cumprimento da sua meta: diminuir o valor médio da tensão de cisalhamento no tubo de underflow.

A comparação seguinte foi feita entre a geometria base e a 3 .

Nela, não houve mudança acentuada na intensidade na tensão na parede na região de transição entre o tubo de entrada e o corpo do equipamento. Houve uma pequena queda no valor máximo de tensão na parede na geometria 3 quando comparada com a geometria base, , de 519 Pa para $498 \mathrm{~Pa}$, porém o valor médio da mesma aumentou, de $418 \mathrm{~Pa}$ para $431 \mathrm{~Pa}$.

No que diz respeito à parede em todo o hidrociclone, a tensão na parede média aumentou de 213 Pa para $225 \mathrm{~Pa}$, ao se passar da geometria base para a 3. O valor máximo de tensão no equipamento também cresceu, de $574 \mathrm{~Pa}$ para $601 \mathrm{~Pa}$.

Por fim, foi efetuada a última comparação entre a geometria base e a 4.

As tensões na parede apresentaram um pequeno aumento na geometria 4 quando comparada à base. Na região próxima à entrada, o valor máximo subiu de $519 \mathrm{~Pa}$ para $578 \mathrm{~Pa}$ e o médio de $418 \mathrm{~Pa}$ para $422 \mathrm{~Pa}$.

A geometria 4 também exibiu aumento no valor de tensão na parede médio ao longo de todo o hidrociclone: $234 \mathrm{~Pa}$ contra $213 \mathrm{~Pa}$. Ademais, também conferiu aumento a no valor de tensão máximo na região de transição entre o tubo de entrada e o corpo do equipamento, 574 Pa para $679 \mathrm{~Pa}$.

\section{CONCLUSÕES}

Inicialmente, foi observado que as tensões devido aos efeitos laminares (próximos à parede) são predominantes, uma vez que aquelas devido aos efeitos turbulentos (seio do fluido) são até sete ordens de grandeza inferiores às primeiras. 
Com isso, foram identificadas três regiões de elevada tensão na parede na geometria base: transição do tubo de entrada para o corpo do hidrociclone, região próxima à entrada e tubo do underflow.

Dentre as três novas geometrias propostas a fim de mitigar a tensão na parede nas regiões supracitadas, apenas uma delas, a geometria 2, com um tubo de underflow com ângulo de $15^{\circ}$ se mostrou promissora, pois reduziu os valores médios de tensão na parede tanto localmente quanto globalmente.

As mudanças propostas para o tubo de entrada, entrada de seção reta retangular e a entrada voluta não produziram os resultados desejados. A primeira apresentou redução no valor máximo de tensão na parede na região próxima à entrada, porém o valor médio aumentou, e não forneceu qualquer mudança significativa global. Já a segunda apresentou valores de tensão na parede locais (região próxima à entrada) e globais superiores à geometria de Deckwer et al. (2005).

\section{REFERÊNCIAS}

CASTILHO, L.; MEDRONHO, R.A. Cell retention devices for suspended-cell perfusion cultures". Adv. Biochem. Eng./Biotechnol., v. 74, p 129-169, 2002.

CHICO, E.; RODRÍGUEZ, G.; FIGUEREDO, A. Biorreatores para células animais. In: MORAES, A. M.; AUguSto, E. F. P.; CASTILHO, L. P. Tecnologia do Cultivo de Células Animais: de Biofármacos à Terapia Gênica. São Paulo, Roca, 2007. P. 213-248.

CHU, L.; CHEN, W.; LEE. X. Effect of structural modification on hydrocyclone perfomance. Sep. Purif. Technol., v. 21, p 71-86, 2000.

DECKWER, W.-D.; ANSPACH, F.B.; MEDRONHO, R.A.; LÜBBERSTEDT, M. Method for Separating Viable Cells from Cell Suspension. Patente: n.US 6878545 B2, concedida em $12 / 04 / 2005$.

DOS ANJOS, R.P. Análise da Influência da Tensão de Cisalhamento em Hidrociclones para Separação de Células Animais. 2013. 73 f. Dissertação (Projeto Final em Engenharia Química) - Escola de Química, Universidade Federal do Rio de Janeiro, Rio de Janeiro. 2013.

ELSAYED, E. A.; MEDRONHO, R. A.; WAGNER, R.; DECKWER, W.-D. Use of Hydrocyclones for Mammalian Cell Retention:Separation Efficiency and Cell Viability (Part 1). Eng. Life Sci., v. 6, n. 4, 2006.

JOCKWER, A. Einsatz neuartiger Hydrocyclone zur Rückhaltung tierischer Zellen in PerfusionsBioreaktoren. 2001. Dissertação (Química) - Technischen Universitaet Braunschweig, Braunschweig, Alemanha, 2001. 